\title{
Consumption Patterns of Chinese Elders: Evidence from A Survey in Wuhan, China
}

Postprint

For published article see:

Ying, B., \& Yao, R. (2006). Consumption patterns of Chinese elders: evidence from a survey in Wuhan, China. Journal of family and economic issues, 27(4), 702-714.

\begin{abstract}
The elderly population in China has grown since 1999. Many Chinese businesses have noticed this trend and began to focus on the Gray Market. The behavior of older Chinese consumers has significantly changed. Descriptions of their behavior in previous research need to be updated. This paper uses data from a survey conducted by the authors in China to investigate the current behavior of older consumers. Results show that older Chinese consumers (1) have similar consumption needs as younger adults; (2) display more mature consumption attitudes; (3) play a less important role in the family; and (4) have strong desire for compensatory consumption. These findings call for further research into the behavior of older Chinese consumers as a major marketing focus.
\end{abstract}

Keywords: Aging, China, Consumer behavior, Gray market, Older consumers 


\section{Introduction}

Aging is a trend in most of the world. According to the WHO, both the number and the proportion of older persons is increasing and around $75 \%$ of the elders in the world will be living in developing countries by year 2025 (World Health Organization, 2006). In China, the population of age 60 and older reached 125 million in 1999, signifying the commencement of an older-age society (Zeng, 2001). The number of older people amounted to 129 million in year 2000, and is growing at the rate of $3.2 \%$ per year thereafter. It is estimated that the number

of older people in China will increase to 335 million in year 2030. These statistics indicate that a large Gray Market has emerged in China.

Traditionally, it was believed that older consumers had developed permanent consumption patterns; they were not willing to change their consumption behavior; and they were very sensitive to price changes (Liu, 1999; Wang, 1999). Therefore, business marketing teams in China focused their attention on younger consumers and children but ignored older consumers of age 50 and above (Carrigan \& Szmigin, 1998; Guo \& Yu, 1999; Long, 1998). Chinese researchers also focused their studies on children' s consumption patterns (Guan, 2003; Sun, 2003). Recent research efforts (Li, 1998; Liu, 2001) show that older Chinese consumers do not behave as traditionally expected. Their consumption behaviors are rather diverse.

The total consumption capacity of the Chinese Gray Market in 2000 was

288.8 billion Yuan. It is estimated that this consumption capacity will increase to $1,777.4$ billion Yuan in 2020, 5,236.2 billion Yuan in 2030, and 30,590.1 billion Yuan in 2050 (Chen, 2003). These numbers suggest older consumers are expected to increase in importance to businesses in the near future. With the fast-developing new trends of leisure consumption in China (Yin, 2005), older people are likely to participate in more leisure activities. Businesses should start 
paying close attention to older consumers in order to understand their consumption behavior and meet their consumption needs.

Understanding consumer behavior is critical in developing marketing strategy. Age, because of its strong association with an individual' s psychological and physical conditions and their social and family roles, has a great impact on consumer behavior. Characteristics of older consumers' behavior differ from those of other consumer groups in that the majority of older consumers are retired with less income and they are non-savers. Although some may work after retirement, this employment is likely to be temporary.

Pure consumption (spending without saving) is the basic feature of the Gray Market. Another unique and important feature of the Gray Market is that older consumers’ children, relatives, and other related people shop for the elderly. These shoppers become the target group that many businesses try to attract (Wu \& Luo, 2002). Therefore, when studying the Gray Market, personal consumption and consumption transfer should be separated.

This paper seeks to further the investigation of older consumers' behavior initiated by previous researchers (e.g. Li, 1998; Liu, 2001) to delineate current consumption characteristics of older Chinese consumers. The concept of ' 'older consumers' ' did not exist until this group became larger and more noticeable. Older consumers are a group of people that are constantly changing; today' s older consumers are very different from those in the 1980s.

\section{Literature Review}

Previous research on older consumers usually stereotyped older consumers and assumed that they, as a group, had developed permanent consumption habits and would continue these habits in their consumption activities throughout their lives. Older consumers were perceived to 
know very little about new lifestyles and were reluctant to learn more about them or accept them (Gao \& Ma, 1999; Guo, 2000; Liu, 2001). In other words, older consumers were determined to live in their traditional and familiar lifestyle and refused to move forward. These beliefs have their physical and psychological basis. People' ability to learn and adapt to new things decreases as they age; and self-consciousness, accumulated through life, becomes an ideological defense for their lack of willingness to let go the tradition and try new things (Fu, 2001). Older people generally suffer from decreased and inadequate physical functioning, which further contributes to their inability and unwillingness to keep up with the changes. Many previous studies argued that once consumption habits were formed, they became the "good old" consumption pattern that older people would comfortably follow. This perspective of older people' s physical and psychological characteristics, once thought to be correct, should be changed.

Recent research showed that older consumers were more diverse and more complex than previously believed. According to Wan (2002), consumers should be divided into six groups: (1) conservative, (2) rational, (3) economical, (4) impulsive, (5) creative and (6) hesitant consumers. In previous research, older consumers were believed to be conservative and economical and their consumption behavior can be summarized as below.

Strong Psychological Inertia: High Brand and Commodity Loyalty

Older people had a tendency to form a fairly stable consumption habit, reflected by their everyday shopping pattern and commodity (or brand) perception (Liu, 2001; Yang, 1997; Yuan, 1997a). Once the preference for a certain brand name was formed, it was almost impossible to change. Older people tended to be loyal customers of traditional brands, stores and commodities; brand loyalty was always an emotional appeal for older consumers (Guo, 1999). 
Price-Sensitive: Desire For High Quality Goods At Low Price

The first two characteristics that older consumers looked for in any commodity were quality and price (Chu, 1998; Liu, 1999; Yang, 1999). Being affected by traditional

Confucianism, older people wanted to be "modest" and did not like to stand out from the crowd. Therefore, the simple lifestyle was more highly appreciated after liberation (1949) and before the commencement of the reform (1978). "Work hard" and "save for the future" were two good traditional virtues. In order to prove that they were extolling such virtues and were saving and not spending money on "unnecessary things", it was common for older people to wear the same clothes for many years. Simple diet was also appreciated by the general public. Being influenced by these same beliefs, older consumers usually paid special attention to a com- modity's durability and price. They paid little attention to style (Yuan, 1997b). When making consumption decisions, older people preferred commodities that were cheaper in price with good quality (long durability) instead of more expensive products with attractive designs. It was the common consumption psychology that young people should go after fashion and style while older people should focus on quality.

Practical: Seek Convenience and Practicality

Older consumers were usually practical; convenience and practicality were the major incentives of their consumption (Gao \& Ma, 1999; Liu, 1999, 2001). Convenience, nice shopping environment, and good service were major factors that older consumers considered when they decided where to shop. This assumption about older people' s desire for convenience, including the shop location and the ease of product use, has a biological basis. As people age, physical changes are inevitable. Older people tend to appreciate quieter places and a 
slower lifestyle. They lack the physical strength and, therefore, are neither energetic nor ready to cope with the high-paced shopping style of outlets or crowded stores with noisy surroundings. Because older consumers were likely to lack the knowledge about newer prod- ucts, they usually felt that reading the lengthy instructions about a product, such as a multi-functional household appliance, was inconvenient. They often chose not to purchase products with a complicated manufacturer' s handbook. Most older people, however, never read the instructions that came with the product except for those who were highly educated. Older people tended to use a product according to their past experience with it or follow their children's directions. This desire for convenience was one of the main reasons that older consumers were unsophisticated and were always the target and victims of market scams.

Compensatory Consumption

Compensatory consumption was one type of psychological consumption. It represented a self-compensation response to the psychological imbalance of older people (Gao \& Ma, 1999; Li, 1998; Zhang, 1997). Because of rapid changes demanded after the 1978 social reform, China's economy began to improve. People's living standard increased and their new lifestyle became the norm to follow. Older people tended to feel that they did not have so many choices when they were young and they wanted to make up for it. The consumption motivation for those with adequate time and wealth was to make up for the past. Moreover, when children became independent and left home, older consumers realized an increase in their time and economic resources. They tried to satisfy their consumption needs and wants that were not even dreamed about when they were younger. Some older consumers became more interested in clothing, fine food, entertainment, and sightseeing. 


\section{The Present Study}

Consumption is the process whereby individuals seek, purchase, utilize and evaluate the good or service that will bring satisfaction ( $\mathrm{Ji}, 2000)$. According to $\mathrm{Ji}$, this process consists of five stages:

(1) the purchasing desire formation stage;

(2) the information search stage;

(3) the decision-making stage;

(4) the purchasing stage; and

(5) the evaluation stage.

The study on consumption behavior, in a narrow sense, focuses on the actual consumption performance, which includes the third and fourth stages in the consumption process (Peng, 2002). The investigation of these two stages has significant implications on business marketing strategies and, therefore, is of the most interest to businesses.

Age has an essential impact on an individual' s consumption behavior (Fu, 2001). Age influences consumption behavior through its impact on an individual's psychological characteristics, social and family roles, and reference groups. Other than age, major factors that affect consumption behavior include the quality, feature and function, price, brand, appearance and advertisement of the particular goods and services and peer consumption behavior (Wan, 2002). Modernization results in changes in attitudes and values (Meeks, Nickols, \& Sweaney, 1999), which affect the behavior of consumers.

Figure 1 shows the proposed conceptual model. The characteristics of the goods and services affect an individual' s consumption behavior. Age affects consumption behavior via its influence on the individual' s personal characteristics (psychological characteristics or attitudes) and the external environment (modernization, social and family role, and peer/reference group), 
which have a direct impact on the individual's consumption behavior. The external environment not only affects the individual's consumption behavior via its influence on his/her personal characteristics, but also affects his/her consumption behavior directly.

Great changes have taken place in China. People's living standard is enhanced and living styles and consumption habits have changed as well (Jing, 2001). As a result, older peoples' attitudes and behaviors have changed accordingly and the Gray Market has become a new market focus of many Chinese businesses. This study focuses on the third and fourth stages of consumption and investigates modern consumption behavioral characteristics of older Chinese consumers, including their demographic profiles, factors that affect their consumption decisionmaking and consumption habits. Understanding older consumers' consumption behavior has important implications for business marketing and sales strategies.

Sampling Site

The authors surveyed older consumers in Wuhan, a major city in central China. Wuhan is a city with a total area of $8,494 \mathrm{~km} 2$ (approximately 3,280 miles2) and a population of 7.68 million (National Bureau of Statistics of China, 2002). In year 2002, Wuhan’ s Gross Domestic Product (GDP) was 149.30 billion Yuan (approximately 18.41 billion US dollars), which represents $1.46 \%$ of China' s GDP of the year. In year 2002, Wuhan was the seventh largest city in terms of Comprehensive National Power.2 Its average annual per capita disposable income was 7,820 Yuan (approximately 898 US dollars) in 2002.

\section{Data and Method}


Six hundred older consumers (age 55 and above) were selected from all seven districts of Wuhan. Of the 600 returned questionnaires, 436 were valid (completed) for a final response rate of $72.7 \%$.

The questionnaire was designed by the authors. A total of 48 questions were asked. The questions included demographic characteristics, consumption needs, consumption attitudes, family role in consumption decision-making, and compensatory consumption desire. All were multiple-choice questions. The questions used in the survey were a variation of a selection of questions used in Wan's study in 2002. A pilot survey was conducted and suggestions from experts were adopted for restructuring the questionnaire. Experts in this field were invited to complete the questionnaire and give suggestions on its validity and reliability.

The target population was older people of age 55 and older residing in Wuhan. Some researchers define older people to be those of age 50 or above (Beck, 1996; Burt \& Gabbot, 1995; Mazur, 1993; Mitchell, 1996; Semon, 1995). Others use age 55 as the cut-off point (Bone, 1991; Carrigan, 1998). Chinese labor law places male retirement at age 60; females retire at age 55 or 50 depending on their job title. Fu (2000) and Wang (1999) concluded that people usually stop working completely around age 65 . However, according to Jing (2001), the current labor market situation in China is that the majority of people retire at age 55. Therefore, the authors believe that using 55 as the cut-off age is more reasonable in Chinese research. Due to the old age of this population and their possible low levels of education and poor health, the survey was conducted face-to-face at the respondents' site so that additional clarification of the questions could be offered as needed. Survey interviewers were sophomore and junior marketing students in the Business School at Zhongnan University of Economics and Law. They completed a 3-h training on survey interviewing before they conducted the survey. 
Survey samples were selected in all seven districts in Wuhan. The authors selected 5-7 sample collection blocks in each district according to the size of local population. The sample was drawn from a total number of 40 blocks with 15 samples selected from each block. The total sample size was, therefore, 600 . The sample selection blocks were residential buildings, elderly homes, universities for older people and parks. Respondents were randomly selected from the residential buildings, the elderly homes and the universities for older people. Respondents in the parks were irregularly stopped until the number of respondents reached the desired level. Each selected older person had to have lived in Wuhan for three consecutive years or more, otherwise another respondent would be randomly chosen to replace the non- resident or short-term resident. Questionnaires were handed out to the respondents to complete. Initial instructions were given to respondents on how to complete the questionnaire. Survey interviewers assisted participants by reading the questions to those who could not mark their answers due to health problems or educational barriers. Each survey took, on average, $15 \mathrm{~min}$. Participants were required to complete the survey on-site and hand it to the interviewer upon completion.

\section{Results}

The sample represented the Wuhan elderly population in all characteristics except that their education was substantially above the average education level of the target population. One hundred and ninety (43.6\%) respondents had a university degree, 192 (44.0\%) respondents did not go to college but had a high school diploma, 39 (8.9\%) respondents graduated from a primary school, and $15(3.5 \%)$ respondents did not finish primary school. According to the National Bureau of Statistics of China (2002), in Wuhan, 7.3\% of older people (age 60 and above) had a university degree, $12.7 \%$ did not go to college but had a high school diploma, 
$20.9 \%$ graduated from middle school, $22.3 \%$ graduated from a primary school, and $36.8 \%$ did not finish primary school.

The respondents consisted of 239 (54.8\%) males and 197 (45.2\%) females (Table 1). Respondent age ranged from 55 to 83 years old. Two hundred and twenty- four $(51.4 \%)$ respondents fell in the 55 - 60 age group, $108(24.8 \%)$ in the $61-65$ age group, $53(12.1 \%)$ in the $66-70$ age group, and $51(11.7 \%)$ in the $70-83$ age group. One hundred and thirty-three $(30.5 \%)$ were government employees, 95 (21.8\%) respondents were manual laborers, 80 (18.3\%) were teachers, $34(7.8 \%)$ were technicians, $27(6.2 \%)$ were doctors, $6(1.4 \%)$ were farmers and 2 $(0.5 \%)$ were lawyers.

For $29(6.7 \%)$ respondents, their monthly income was 200 Yuan or less, 75 (17.2\%) respondents' monthly income fell into the $201-400$ Yuan group, 66 (15.1\%) respondents had a monthly income between 401 and 600 Yuan, 115 (26.4\%) respondents received between 601 and 800 Yuan per month, $68(15.6 \%)$ respondents received between 801 and 1,000 Yuan per month, $36(8.2 \%)$ respondents' monthly income were in the 1,001 - 1,200 Yuan group, $18(4.1 \%)$ respondents had a monthly income between 1,201 and 1,400 Yuan, and $29(6.7 \%)$ respondents received 1,400 Yuan or more per month. Table 2 showed that the majority $(62.9 \%)$ of the respondents believed that reading advertisements was at least somewhat important when making consumption decisions. Of these respondents, $6.7 \%$ thought advertisements were very important to them and $26.7 \%$ thought advertisements were important. Only $22.7 \%$ of the total respondents believed advertisements were unimportant.

The results showed that older people did not make the majority of family pur- chasing decisions as assumed by previous research. Older people made $52.7 \%$ of the family food 
consumption decisions (Table 2 ) and $29.2 \%$ of clothing consumption decisions. They made very few decisions on family electronic appliances (8.5\%) and furniture (11.5\%).

Older people consulted with other people before they make consumption deci- sions (Table 2). More than half of the respondents discussed their decisions with their spouse (43.0\%) or their children (17.7\%). Many of them (37.0\%) chose to talk to other older people about their consumption decisions.

Those who thought that fine clothes and make-up were "very necessary" or "necessary" accounted for $71.9 \%$ of total respondents (Table 2). Only $1.6 \%$ of the respondents believed that fine clothes and make-up were "not necessary".

Table 2 also showed that more than half of the older people (51.2\%) exhibited traits of rational consumers. 3 One fifth of the respondents were conservative con- sumers, a little more than one tenth (12.3\%) were impulsive consumers, and $9.1 \%$ were economical consumers. Only a little more than a quarter (25.8\%) of older consumers considered price as the major factor when making purchasing decisions (Table 2 ). More respondents chose either quality $(29.8 \%)$ or product feature and product function as the primary factor that affected their decision-making.

\section{Discussion}

Research results show that older consumer's consumption pattern, consumption perception, and consumption behavior have changed. Some previous descriptions of the characteristics of older Chinese consumers do not match characteristics of today' s older consumers. The following is a summary of changes in behaviors of older Chinese consumers. Similar Consumption Needs As Young Adults 
Older consumers used to be described as a group that had high brand loyalty, had little interest in fashion, and was uninfluenced by advertisement and promotions. In other words, this group was unable and unwilling to accept new things as easily as young people who embrace them.

This study shows that older consumers' consumption perceptions have changed. They are more willing to accept new things. Advertisements now play an important role in their consumption decision-making. Table 2 shows that the majority (62.9\%) of older people believe advertisement is at least somewhat important in their consumption decision-making. Older people are open to new retail styles and pay more attention to their appearance. This reveals that older consumers' consumption perceptions have become more similar to those of young people.

More Mature Consumption Attitudes

Attitudes toward consumption affect consumer behavior. As people age, physical changes may lead to changes in attitudes. Older people often desire to have a long life, enjoy a happy and stable life, be respected by others, serve the society, and do not want to be alone. Investigation of older people' s consumption attitudes provides better understanding of older consumers' consumption behaviors.

Traditionally, older consumers were believed to be conservative and economical consumers. However, this study reveals that most older people are rational consumers (Table 2). In the past, older consumers' consumption characteristics (e.g. consumption habit, purchasing habit) may be formed based on their consumption experience. It was believed that they were used to certain commodities through repetitive consumption of these goods; therefore, formed their consumption and purchasing habits; and were not willing to change the habits. Today's 
older consumers are depicted much differently. As they age, they accumulate more consumption experiences, and become more aware of their consumption needs and wants. Before purchasing, they like to shop around, compare, and consider as many factors as possible. This study shows that there are few economical consumers among older people (Table 2), which suggests that today's older consumers are no longer low-price seekers. Price is only one of the factors that they consider while shopping.

Older consumers in today's China did not live a wealthy life in the past; they were told to appreciate a simple lifestyle; and they were very price conscious. With an increase in the level of living standard, increased income level, and the formation of a Buyer's Market in China, older people' s consumption attitudes have changed. Today, they care more about quality, features and functions of the product than its price when making purchasing decisions (Table 2). Weakened Family Roles

Family members in small families contribute less to the family' s purchase decisionmaking than in large families (Jin, 2001). Samli (1995) stated that smaller families in western countries encourage individual decision-making; but in China, older people in the family used to have a great influence on individual and family purchases. Samli believed that older family members played the leading role in a Chinese family' s purchase decisions. However, older people' s role in family consumption decision- making in recent years is weakened. Based on the results in this study (Table 2), older people' s decision-making power in the family is not strong: they make $52.7 \%$ of the decisions on food, $29.2 \%$ on clothing, $8.5 \%$ on electric appliances, $11.5 \%$ on furniture and $15.1 \%$ on others. Most older people discuss with their spouse $(43.0 \%)$ or other older people $(37.0 \%)$ before making purchasing decisions (Table 2). A small portion of them $(17.7 \%)$ talk to their children. 
There are many reasons for this weakened family decision-making role. First, income status within the family may have a positive effect on the member' $s$ decision- making power in the family. Since the inception of China's open-door policy, young people's income level has increased dramatically. Many young people who work for private businesses or international companies make more money than older members in their families who serve in traditional stateowned corporations. The increased income level of younger people in the family strengthens their role in family decision-making. Second, the traditional concept of "obeying the old" may be no longer in practice in today's family consumption decision-making. Modern household appliances are more complex and technology-intense. This makes comparison shopping more difficult than previously. Many older family members are not technologically up-to-date. Purchasing is left to younger members in the family who are more experienced in and more comfortable with technology. Raised Compensatory Consumption Desire

In the past, there were fewer choices in the marketplace and people earned little income. Older consumers seldom sought satisfaction from consumption. Moreover, it was not accepted in traditional Chinese society for people to pay much attention to their own appearance and "live a capitalist's life". Compensatory consumption never existed in the past. In modern society, China ' s social reform and the open-door policy have led to huge social and economic changes. Most older people (71.9\%) believe that paying attention to their appearance (e.g. clothes and make-up) is necessary or very necessary (Table 2). Because most older people are retired without children at home, they have more time and money to enjoy life. It is a new trend for older couples, who were married in the $50 \mathrm{~s}$ or $60 \mathrm{~s}$, to put on a wedding dress, spend thousands of Yuan and have their wedding anniversary pictures taken to compensate for their overly simple life in the past. 
Some older people form their own organizations that arrange group tours in the country and even around the world. This is to compensate themselves for the time they spent in working and raising children.

Another important part of such compensatory desire of older Chinese consumers is reflected in their generous purchases for their grandchildren. According to an investigation by Fudan University in 2000, consumption for grandchildren takes second place, only next to the expenses for themselves, in older consumers' consumption structure. The present Chinese urban family structure is " $4+2+1$ " or "four grandparents, two parents and one child." The only child is the sole focus of the whole family. Young people spend more time working than being with their parents and children because of workplace competition and the pressure to keep a job and succeed in their career. The tradition for older people to look after their grandchildren is still taken for granted in modern China. Therefore, in order to compensate their children for what they themselves did not enjoy due to economical limitations in the past, older people are now very generous to their grandchildren. In compensatory consumption, older people care little about price. They tend to purchase highly priced products if it will best fit their needs. Implications and Limitations

That the majority of the respondents believe reading advertisements is at least somewhat important when making consumption decisions has implications for the marketing strategy for both businesses and consumers. Businesses should pay attention to their advertisements and tailor them to meet the needs of older people. Older consumers should focus on the information related to the goods and services presented in the advertisements and evaluate whether the information presented is accurate, without paying too much attention to how the advertisement is presented. The results suggest that older people do not make the majority of family purchasing 
decisions, except for food. Only $8.5 \%$ of the decisions on electronic appliances are made by older members in the family. Businesses would benefit from targeting older consumers on food and younger consumers for household appliances. Price is not the single most important factor in older people' s consumption decision-making. They are more concerned with the quality and product features. This has great implications for business marketing strategy. Older consumers are mature and the product itself is the focus of attention; therefore, businesses should realize that a cheaper price would not attract the majority of the older consumers. There are limitations in this research design. Samples were taken in one city only, which makes the sample nonrepresentative of the whole population in China. Therefore, the results found in this study cannot be generalized to the whole population. This limitation primarily comes from the restriction of the research funding obtained by the authors. Future research should study the consumption characteristics of older individuals in other areas as well.

There was no rural representation in the sample. The majority of Chinese population lives in a rural area. Their consumption behavior was not studied sufficiently by Chinese researchers. This population does have a significant contribution to the market and therefore should attract more attention. Future research that uses a sample, which can represent the total population in China, is needed.

The validity and reliability of the questions used in the survey were not assessed by some established instrument or research. Wan (2002) is the pioneer in this field to provide the instrument. More research is needed to test the validity and reliability of the questions. Another limitation of this paper is that it is merely descriptive. More advanced methods should be adopted by future research to investigate the statistical significance of the research results. 
This study provides an introductory research on the characteristics of older Chinese consumers and plays the pilot role to encourage more valuable investigations on this topic. The major findings indicate that the characteristics of older Chinese consumers are not the same as what was traditionally believed. Future research should study the differences in the characteristics of older and younger consumers and investigate ways to better meet older people' $\mathrm{s}$ consumption needs.

\section{References}

Beck, B. (1996, January 27). The luxury of longer life. Economist, 7 - 9.

Bone, P. F. (1991). Identifying mature segments. Journal of Consumer Marketing, 8(4), 19 - 31. Burt, S., \& Gabbot, M. (1995). The elderly consumer and non-food purchase behaviour. European Journal of Marketing, 29(2), $15-43$.

Carrigan, M. (1998). Segmenting the grey market: The case for fifty-plus 'lifegroups' . Journal of Marketing Practice: Applied Marketing Science, 4(2), 43 - 56.

Carrigan, M., \& Szmigin, I. (1998). The usage and portrayal of older models in contemporary consumer advertising. Journal of Marketing Practice: Applied Marketing Science, 4(8), $231-248$.

Chen, F. (2003). The grey industry. Journal of China Business, 2(3), 16 - 19 (in Chinese). 
Chu, J. (1998). Characteristics of Chinese grey market. Journal of China Business, 1(2), 6 - 9 (in Chinese).

Fu, B. (2000). China' s grey market. Journal of Nanhua University, 2(1), 28 - 33 (in Chinese).

Fu, G. (2001). Consumer behavior, Beijing: High Education Press (in Chinese).

Gao, H., \& Ma, Y. (1999). Consumption psychology of grey market. Journal of Market Analysis, 4(2), 9 - 14 (in Chinese).

Guan, Y. (2003). Consumption patterns of Chinese children. Journal of Family and Economic Issue, 24(4), 373 - 379.

Guo, G. (1999). Fundamentals of marketing in China. Beijing: China People’ s University Press (in Chinese).

Guo, P. (2000). Characteristics of older consumers and marketing strategies of the grey market. Journal of Sales and Marketing, 2(5), 22 - 25 (in Chinese).

Guo, G., \& Yu, X. (1999). Development of grey market and grey industry in China. Journal of Beijing Business College, 1(3), 36 - 38 (in Chinese).

Ji, S. (2000). Consumer behavior. Nanjing: Jiangsu Science and Technology Press (in Chinese). Jin, X. (2001). Chinese elderly people' s life in transition period. Journal of Xi' an Jiaotong University, 4(1), 21 - 33 (in Chinese).

Jing, X. (2001). Chinese elderly people' s life in transition period. Journal of Xi' an Jiaotong University, 2(3), 22 - 28 (in Chinese).

Li, B. (1998). Characteristics of older consumers. Journal of China Business, 4(4), 14 - 17 (in Chinese).

Liu, F. (1999). Characteristics of older consumers and marketing strategies of grey market. Journal of Jiangsu Business, 1(1), 25 - 28 (in Chinese).

Liu, Z. (2001). Older people' s consumption psychology and marketing strategies of grey market. Journal of Economist, 2(3), 15 - 21 (in Chinese).

Long, N. (1998). Breaking down by age and sex: Exploring ways to approach older consumers. Journal of the Market Research Society, 40(2), 73 - 91 (in Chinese).

Mazur, L. (1993, February 11). Golden oldies. Marketing Business, 32 - 33.

Meeks, C. B., Nickols, S. Y., \& Sweaney, A. L. (1999). Demographic comparisons of aging in five selected countries. Journal of Family and Economic Issue, 20(3), $223-250$.

Mitchell, A. (1996, January 05). Why grey means gold. Management Today, $76-77$.

National Bureau of Statistics of China (2002). Wuhan statistical yearbook. Wuhan: China Statistics Press (in Chinese).

Peng, X. (2002). Modern marketing. Beijing: China Financial Economics Press (in Chinese).

Samli, A. C. (1995). International consumer behaviour: Its impact on marketing strategy. Westport: Greenwood Publishing Group.

Semon, T. T. (1995, January 2). Gerontophobia in marketing research. Marketing News, 29(1), 23.

Sun, Y. (2003). Overview of children in China. Journal of Family and Economic Issue, 24(4), $331-335$.

Wan, H. (2002). Modern marketing. Beijing: China Financial Economics Press (in Chinese).

Wang, D. (1999). Characteristics of older consumers. Journal of Market and Demographic Analysis, 2(3), 11 - 15 (in Chinese). 
World Health Organization (2006). The world is fast ageing - have we noticed? Retrieved May 18, 2006, from http://www.who.int/ageing/en/

Wu, Y., \& Luo, C. (2002). Characteristics of older consumers and marketing strategies of the grey market. Journal of Economic and Finance, 2(3), 21 - 26 (in Chinese).

Yang, G. (1997). Characteristics of older consumers and marketing strategies of the grey market. Journal of Market and Demographic Analysis, 3(5), 12 - 15 (in Chinese).

Yang, X. (1999). Behavioral and psychological characteristics of older consumers. Journal of Economics and Finance, 3(5), 31 - 36 (in Chinese).

Yin, X. (2005). New trends of leisure consumption in China. Journal of Family and Economic Issue, 26(1), 175 - 182.

Yuan, Y. (1997a). Chinese older consumers' behavior. Journal of China Business, 2(4), 11 - 15 (in Chinese).

Yuan, Y. (1997b). Lifestyle of elderly people and marketing strategies of grey market. Journal of Market and Demographic Analysis, 1(2), 23 - 30 (in Chinese).

Zeng, Y. (2001). Major characteristics of the aging population and related policy considerations in China. Population and Economics, 1(5), 3 - 9 (in Chinese).

Zhang, Y. (1997). Consumption characteristics of older people. Journal of Modern Finance and Economics, 3(3), 24 - 27 (in Chinese). 